\title{
Protocol on Medico-Legal Documentation of Sleep Deprivation
}

\author{
Pau Pérez-Sales*, Elna Søndergaard**, Efrat Shir***, Marie Brasholt****, \\ Ergün Cakal*****
}

\section{TABLE OF CONTENTS}

Preface

Definitions

Legal and Medical Considerations

Protocol

1. Purpose

2. Overview of the Protocol 35

3. Protocol 36

Section 1. Informed Consent and General Considerations for Interviews 36

Section 2. Subjective Experience $\quad 37$

Section 3. Baseline: Sleep Pattern before Detention 38

Section 4. Diary of Sleep: What Happened? 39

$\begin{array}{ll}\text { Section 5. Sleeping conditions } & 41\end{array}$

Section 6. Medical and Psychological Consequences 42

Checklist of Cognitive Symptoms linked to Detention 43

Checklist of Emotional Symptoms linked to Detention 45

Severity of Pain and Suffering $\quad 46$

Long Term Symptoms $\quad 47$

Section 7. Legal Assessment of Sleep Deprivation 49

$\begin{array}{ll}\text { Purpose and Outcome } & 49\end{array}$

Assessment of the Intention behind the use of Sleep Deprivation $\quad 50$

$\begin{array}{ll}\text { Annex - Additional Questionnaires } & 52\end{array}$

References $\quad 54$

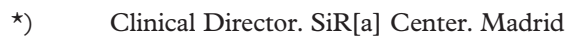

$\star \star$ Senior Legal Advisor DIGNITY - Danish Insitute Against Torture, and Associate Professor, Law Faculty, Copenhagen University

$\star \star \star)$ Manager of Medico-Legal Documentation, Public Committee Against Torture in Israel (PCATI)

\footnotetext{
$\star \star \star \star)$ Senior Medical Officer, DIGNITY - Danish Institute Against Torture

$\star \star \star \star \star)$ Legal Advisor, DIGNITY - Danish Institute Against Torture

Correspondence to: es@dignity.dk
} 


\section{Abbreviations}

UNCAT: UN Convention against Torture and Other Cruel, Inhuman or Degrading Treatment or Punishment (1984)

Istanbul Protocol: UN Manual on the Effective Investigation and Documentation of Torture and Other Cruel, Inhuman or Degrading Treatment or Punishment (1999)

\section{Preface}

This Protocol originates from a joint project regarding documentation of psychological torture initiated by the Public Committee against Torture in Israel (PCATI), REDRESS and DIGNITY - Danish Institute Against Torture (DIGNITY) in 2015 after the Copenhagen Conference on Psychological Torture. The project is a vehicle to establish a common understanding between health and legal professions as to how to best ensure the most accurate documentation of psychological torture.

Historically, sleep deprivation has been used for different objectives but, primarily, to cause stress and duress for the purpose of extracting information and confessions. Detention centers with poor conditions is another context in which sleep deprivation, as a consequence of sleep disruption, takes place. This is often due to overcrowding, insufficient or no mattresses, and poor conditions of transportation between the courts and detention facilities.

The aim of the Protocol is to improve documentation of sleep deprivation used in such settings (most often during interrogation) and therefore to clarify the facts of the case so that stronger legal claims can subsequently be submitted to local and international complaints mechanisms.

The Protocol has been developed based on a methodology involving: compilation and review of legal and health knowledge on sleep deprivation, also in non-torture contexts; drafting by first author; discussion in the group of international experts; ${ }^{1}$ pilottesting by PCATI; and evaluation by the three organizations and the group of experts.

Despite generic elements of sleep deprivation, the context in a specific country will determine many aspects of the factual situation. Each context differs and as such this Protocol could serve as a guideline or a checklist of elements to be considered in a specific context.

We hope that this Protocol will assist in the discussions between the various stakeholders and provide guidance on what can be documented and how to document sleep deprivation.

\section{Definitions}

The Protocol refers to the following definitions that have been agreed in the group of experts:

\section{Total sleep deprivation (TSD):}

Elimination of sleep for a period of time (at least one night) after the person has been awake for an extended period. It is an absolute value (e.g. 43 hours).

\section{Partial sleep deprivation (PSD)/Sleep} restriction (SR): Reduction in sleep time below an individual's usual baseline or the amount of sleep needed on a regular basis to maintain optimal performance. It is a relative value (e.g. 4 hours sleep in a person with an

1 The group includes the following experts and organizations in addition to the authors of this Protocol: Nora Sveaass, Nimisha Patel, Brock Chisholm, Ahmed Benasr, REDRESS (Rupert Skilbeck and Alejandra Vicente), Freedom from Torture (Angela Burnett and Emily Rowe), IRCT (Asger Kjærum and James Lin), and University of Essex (Carla Ferstman). 
average baseline sleeping time of 7 hours, means a PSD of 3 hours).

Sleep disruption (SD): Interruption or fragmentation of sleep, where frequent arousal disrupts the normal dynamics of sleep for the person. Sleep disruption is associated with an increase in awakenings and, typically, a reduction of deep sleep although the total amount of time might seem similar to a normal night's sleep (e.g. 7 hours of sleeping time with interruptions due to hunger, heat or loud noise). It can be deliberate or not.

\section{Minimum duration of necessary sleep:}

There is a small variability in individual needs among adults (from 5 to 8 hours). There is a widely accepted consensus of an average of 7 $+/-1$ hours of daily continuous sleep as part of a normal sleep pattern. For an adult (18-65) the minimum duration of necessary sleep is no less than 6 hours and for an older adult (>65), not less than 5 hours. The minimum duration for children (under 18) is higher (Hirshkowitz et al., 2015; Watson, Badr, Belenk, \& Bliwise, 2015).

This is a recommendation during normal circumstances and should also be the minimum during detention or interrogation (see Editorial, this issue). ${ }^{2}$

Resting Periods: Time without interrogation or any other administrative interruption including transportation.

\footnotetext{
Although some military regulations have proposed lower levels as incidental to normal routines, even a 4-hour daily minimum, medical standards show that less of a 6 hours daily level is unacceptable regardless of human variability. This is more so the case if sleep deprivation is combined with other stressors that produce cognitive and emotional exhaustion or if it lasts for more than one day and there is a cumulative effect.
}

\section{Legal and Medical Considerations ${ }^{3}$}

\section{Legal aspects}

The use of sleep deprivation has been recognized in the international human rights framework as a method of torture or cruel, inhuman or degrading treatment or punishment. There is, however, no universally accepted legal definition of what constitutes sleep deprivation or what is sometimes referred to as 'prolonged' sleep deprivation.

The legal assessment needs to be based on the four elements found in the definition of torture in article 1 (1) of the $U N$ Convention against Torture and Other Cruel, Inhuman or Degrading Treatment or Punishment (UNCAT). Accepting the premise that sleep deprivation is primarily used for obtaining information or confession, two elements under the definition emerge to be particularly significant: intentionality and severity of physical or mental pain or suffering. Notably, Article 3 of the European Convention on Human Rights (ECHR) has also been interpreted to require these two elements. If these elements cannot be identified, the treatment can still amount to other forms of ill-treatment (i.e., cruel, inhuman or degrading treatment or punishment). This is explored below when reviewing their application to sleep deprivation.

Severe pain or suffering, whether physical or mental, is accepted to arise out of an individual method or a combination, whether occurring on one occasion or over time (ICTY, 2002: \$182). Therefore, it can be short-lived and need not be

3 For a fuller discussion, please refer to Cakal. E. (2019). Befogging reason, undermining will: Understanding sleep deprivation as torture and other ill-treatment in international law. Torture Journal 29(2). 
prolonged (CAT, 2006: \$13; ICTY, 2006: $\$ 300)$. Mental pain can constitute torture or ill-treatment on its own and need not be coupled with physical pain.

Despite such complexities, the nexus between sleep deprivation and torture has become well-established. The UN Committee against Torture (CAT) has criticized the use of sleep deprivation by a number of states, providing clear indications of outer limits. Most prominently, its observations with respect to the United States focused on the guidelines found in the interrogation rulebook in the US Army Manual that provide: 'Use of separation must not preclude the person getting four hours of continuous sleep every 24 hours' (United States Army, 2006, Appendix M). CAT held that, particularly with the understanding that a person could be subjected to this for a renewable period of 30 days, this amounted to 'authorising sleep deprivation - a form of ill-treatment' (CAT, 2014: §17). Of particular concern was that this rule could be interpreted in such a manner as to allow for 40 continuous hours of interrogation with only four hours of sleep on either end. The US, when questioned by the CAT, rejected that this was the practice. Similarly, CAT has also criticized Israel for using sleep deprivation. ${ }^{4}$ Based on

$4 \quad$ It found one individual to have been permitted to sleep for about one hour in 24 over the course of 4 days, which constituted torture from a medical point of view. In another case, brought before the High Court of Israel (HCJ 2210/96), the detainee had been kept awake for 39 hours followed by 5 hours' rest, then for 47 hours with 2 hours' rest, and then for 22 hours with 5 hours' rest, 47 hours with 5 hours' rest, 46 hours with 5 hours' rest, and finally 48 hours with 6 hours' rest. The situation had perhaps been urgent, but that unquestionably constituted mental torture. (CAT. (1998). Report. E/CN.4/1998/38, \$24); see also CAT/C/ISR/CO/5, para. 30. the understanding that it is not inherently harmful, CAT did not categorically state that sleep deprivation amounted to torture in all cases, as evidenced by their need to detail the durations concerned.

Methods that undermine will or capacity have, to date, been accepted as having the capacity to amount to torture and, more, often as other forms of ill-treatment. Principle 6 of the UN Body of Principles for the Protection of All Persons under Any Form of Detention or Imprisonment, for one, requires other ill-treatment to be interpreted to include "the holding of a detained or imprisoned person in conditions which deprive him, temporarily or permanently, of the use of any of his natural senses, such as sight or hearing, or of his awareness of place and the passing of time." Drawing on the range of impairments emanating from the medical literature, it is reasonable to interpret this to capture any form of sensory deprivation, blunting of the senses or temporal disorientation, including the use of sleep deprivation.

This is also echoed in Principle 1 of the Principles and Best Practices on the Protection of Persons Deprived of Liberty in the Americas, which protects individuals from 'forced intervention or coercive treatment, from any method intended to obliterate their personality or to diminish their physical or mental capacities.' Impairment to one's attention, memory, and communication, as stressed by medical literature on harms, directly impinge on capacity, and hence are readily proscribed by these principles.

The link between sleep deprivation and the obliteration or diminishing an individual's personality was further drawn by the case of Maritza Urrutia v. Guatemala. The InterAmerican Commission requested that the Inter-American Court find a 'violation because of the use of: methods tending to 
obliterate or diminish her personality, such as sleep deprivation' (\$78(b)).

The European Court of Human Rights has considered the use of sleep deprivation in interrogation contexts. For instance, in Mader v. Croatia, where the applicant was 'deprived of sleep and forced to sit on a chair continuously for two days and nineteen hours' at a police station, the court found that this on its own amounted to inhuman treatment (\$108). In Bati v Turkey, where the applicants were subjected to sleep deprivation for several days, as well as physical and verbal assault during interrogation, the court accepted that this treatment 'was liable to harm their mental integrity' ( $\$ 114)$.

In Bagel v. Russia, the applicant, amongst other things, alleged that he had 'insufficient time to sleep on the days of transport'. The court, accepting that the applicant was able to sleep at least from $11 \mathrm{pm}$ to $5 \mathrm{am}$ each night, ruled that he was not subjected to any sleep deprivation $(\$ 70)$. This precedent was followed more recently in Sadretdinov v. Russia, where the applicant complained of the 'authorities' failure to ensure that he enjoyed eight hours' sleep on court hearing days' (\$96). Similarly dismissing this limb of his claim, the court stuck to the sufficiency of the six-hour rule in stating that:

"The applicant had no less than six hours of sleep per night. Moreover, the authorities took steps to ensure that he had enough sleep during at least three nights per week (when he did not take part in court hearings)." In Strelets v. Russia, the applicant complained of insufficient sleep on days of court hearings, over several consecutive days, being woken up at $6 \mathrm{am}$ and being brought back to the cell after $10 \mathrm{pm}$. Notably, the pronouncement of the national court's judgment started at $8.30 \mathrm{pm}$ and finished at $0.30 \mathrm{am}$. Holding it to be inhuman and degrading treatment, the European Court of Human Rights reasoned as follows $(\$ 62)$

"the cumulative effect of malnutrition and inadequate sleep on the days of court hearings must have been of an intensity such as to induce in the applicant physical suffering and mental fatigue. This must have been further aggravated by the fact that the above treatment occurred during the applicant's trial, that is, when he most needed his powers of concentration and mental alertness."

Continuous Interrogation. Sometimes sleep deprivation is considered incidental to interrogation. There is no guidance regarding the maximum length of interrogation permitted in any international standards. ${ }^{5}$ According to studies, an average police interrogation lasts a maximum of two hours exceptionally repeated up to three times with enough time for rest and refreshment among interrogations (Gudjonsson, 2003; Leo, 1996).

5 The United Nations Body of Principles for the Protection of All Persons under any form of Detention or Imprisonment does not establish strict rules regarding the length of interrogation sessions although it does require recording of the duration of any interrogation and of the intervals between interrogations. The International Commissions of Jurist has included "adequate periods for rest and refreshment", again without more clear guidance. As does the Advisory Council of Jurists of the Asia Pacific Forum of National Human Rights Institutions in their Standards for Interrogation of detainees. The European CPT Standards also suggest that interrogations should not be held for lengthy periods, but does not give a concrete recommendation (Morgan \& Evans, 2001). The US Supreme Court ascribes to the "totality-of-the-circumstances" test, that assume that all relevant factors must be assessed, including the application of physical abuse or psychological coercion; the time, length, circumstances, and place of the interrogation; and the age and education of the detainee, along with other considerations. 
Given the above discussion, legal assessments of whether sleep deprivation amounts to torture or ill-treatment should be determined on a case-by-case basis.

These legal considerations have guided the questions in this Protocol.

\section{Medical aspects}

Time-limited sleep deprivation does not leave any known chronic problems, but in the acute stage - i.e. while the sleep deprivation takes place, and in the hours and days following the incident-both physical, emotional and cognitive consequences may be seen and then disappear again spontaneously. These consequences have been described in several scientific studies (see sources below) undertaken in laboratories where total or partial sleep deprivation has been induced for the sake of the study. Other studies have been undertaken among people who have been deprived of sleep as a result of their work, for example during night shifts. In the following, a brief overview of some of the most important findings from such studies will be given. The study results have inspired the questions in the Protocol.

All acute consequences of sleep deprivation described below have been presented in meta-analyses or in systematic reviews, i.e. in scientific papers presenting cumulative results from several different studies, thereby increasing the validity of the findings.

Perception of pain. Sleep deprived individuals have been shown to have a lower pain threshold and also to score higher when asked about their perception of pain (Schrimpf et al., 2015).

Anxiety, mood changes and psychosis. In some studies, sleep deprived individuals have been shown to have higher levels of anxiety
(Pires et al., 2016). They have also been shown to have less inhibition and greater emotional reactions to negative stimuli (Beattie, Kyle, Espie \& Biello, 2015). Last but certainly not least, it has been shown that sleep deprived individuals may develop both visual and auditory hallucinations as well as other symptoms related to how the surroundings are perceived. This includes temporal disorientation, i.e. lack of ability to properly assess time. With sleep deprivation lasting for days, symptoms may proceed to frank psychosis and delirium (Waters, Chiu, Atkinson \& Blom, 2018), the latter being a life-threatening condition that requires immediate medical attention.

Cognition. Several studies have been undertaken assessing the impact of sleep deprivation on cognitive performance. The studies are heterogeneous and therefore difficult to compare, but overall it can be concluded that studies show a clear negative impact of sleep deprivation in more complex areas of cognition. The effect on simple tasks related to attention (e.g. tests assessing a person's ability to react to a simple visual stimulus on a screen) is even more pronounced, and the effect of sleep deprivation on cognition increases with increasing amounts of sleep deprivation (Lim \& Dinges, 2010; Lowe et al., 2017; Philibert, 2005). Interestingly, a person's ability to assess his or her own performance has been shown to be mostly preserved during sleep deprivation (Jackson et al., 2017).

Many studies have also investigated the long-term consequences of chronic sleep deprivation, for example as the result of a chronic sleep disorder like sleep apnea and others. An increased risk of - among others-hypertension and diabetes mellitus has been found in people with chronic 
sleeping problems. This, however, is beyond the scope of a protocol on medico-legal documentation of sleep deprivation and will not be dealt with further here.

Summing up, sleep deprivation may lead to acute physical, emotional and cognitive consequences, and when documenting sleep deprivation, all these aspects must be considered. Symptoms of sleep deprivation are diverse and may range from hardly noticeable cognitive impact to life-threatening delirium.

Sleeping problems are commonly found among torture survivors irrespective of whether they have been subjected to sleep deprivation or not. Asking about current sleeping problems should therefore always be part of the clinical assessment of a torture survivor.

\section{PROTOCOL}

\section{Purpose}

This is a generic protocol to guide the part of an interview with an interviewee that relates to documentation of sleep and sleep deprivation. As such, this Protocol complements the Istanbul Protocol when specific documentation on sleep deprivation is required.

It is designed to be used by lawyers and health professionals during interviews in a detention facility or after release. The average time of application in its entirety is estimated at 40 minutes.

Combined or cumulative effects of the general detention and interrogation context and the various methods used are of importance. Ill-treatment and torture are often not based on single individual techniques (which may or may not be damaging if considered one by one) but is the result of the combined interaction of methods. Thus, sleep deprivation is often not a single element but part of a wider context that must be assessed in the interview (see below).
While some information may be collected by both health and legal professionals (i.e., sections 1-5), two sections of the Protocol require specific qualifications (i.e., sections 6 and 7). An organisation may consider whether to train staff so that they can be qualified to ask certain questions outside their usual professional skill-set. However, this approach has its limitations and should always be guided by the principle of doing-no-harm.

The following key aspects of the context should be highlighted:

a. Importance of time: The Protocol is used to assess the consequences of sleep deprivation after an interval of time following the pertinent event(s). It can be days but more often the interview is undertaken weeks or months after the event(s). At this point, no biological measures or tests would be possible (e.g., Actigraphy, EEG or Evoked potentials).

b. Torturing environment: Imposing sleep disruption is usually part of a more overall torturing environment that often involves threats, humiliation, deprivation of water/food and/or sensory deprivation (e.g., blindfolded). A torturing environment is defined as "a set of conditions or practices that obliterate the control and will of a person and that compromise the self" (Pérez-Sales, 2017)).

c. Verification of the information obtained during the interview: The interrogator must record the hour of beginning and ending of interrogation and time allowed for rest. In some countries, the interviewer may have access to the logbook of the interrogation and will be able to compare the information obtained during the interview with the information in the logbook. 
d. Each country has its specific political and local context and each detaining institution has its specificities regarding methods allowed or prohibited. This should be taken into consideration when applying the Protocol.

\section{Overview of the Protocol}

You will be taken through seven different sections:

- Informed Consent and General Considerations for Interviews;

- Subjective Experience;

- Baseline: Sleep Pattern before Detention;

- Diary of Sleep: What Happened?

- Sleeping Conditions;

- Medical and Psychological Consequences; and

- Legal Assessment of Sleep Deprivation.

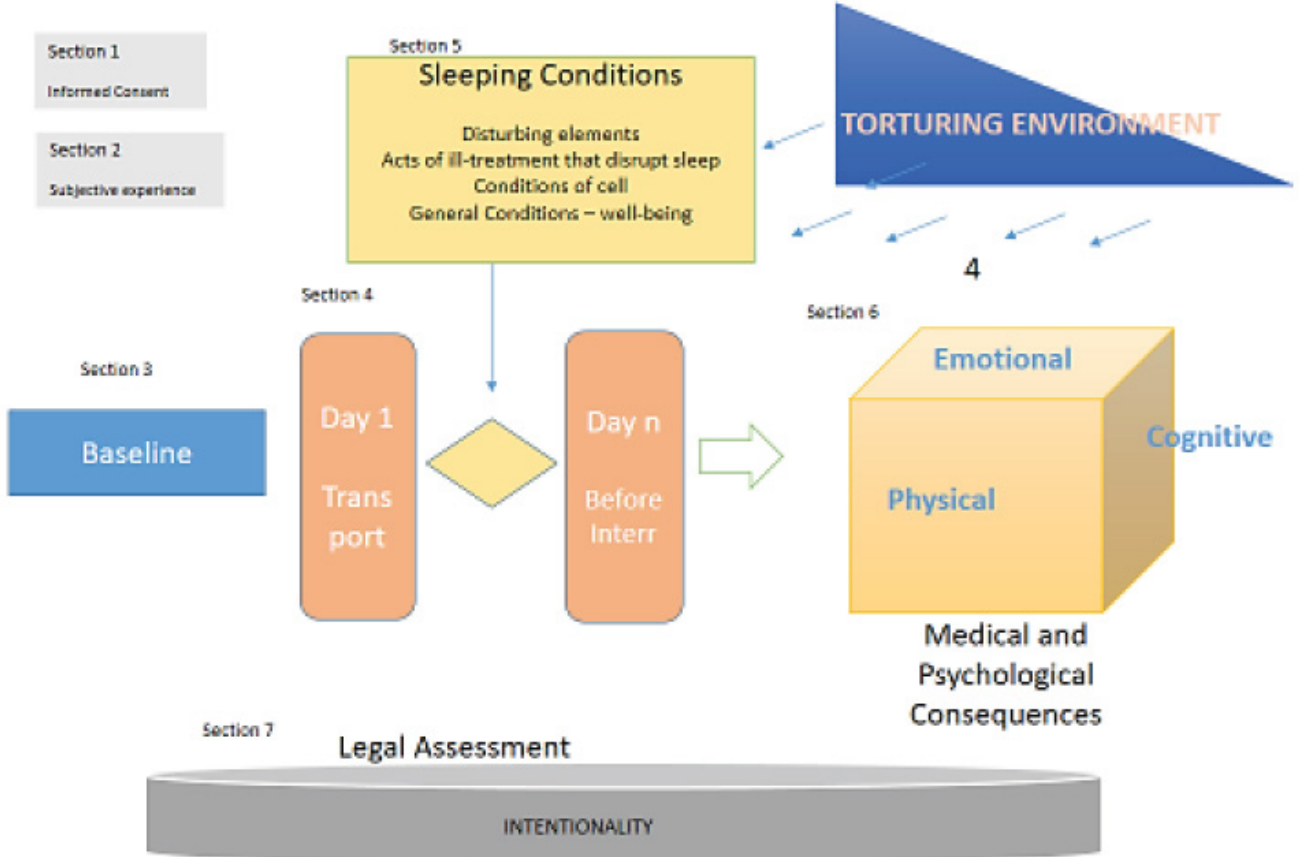




\section{Protocol}

\section{Section 1. Informed Consent and General Considerations for Interviews}

Informed consent involves making sure that when the interviewee consents to an interview (and to the subsequent use of the information that has been provided), the interviewee is fully informed of and has understood the potential benefits and risks of the proposed course of action. Each case must be assessed individually considering the seriousness of the allegation and what the potential risks could be at every step of the process.

The interviewer should obtain informed consent from the interviewee according to the ethical guidelines mentioned in the Istanbul Protocol (see Chapter II).

Key elements of informed consent:

- Information: About yourself and the purpose and objectives of the interview.

- Comprehension: Assess whether your interviewee has really understood the information. Mental ability, language, age, and other aspects may affect the individual's ability to give informed consent. The higher the risk, the higher the obligation to ensure a proper understanding of potential risks.

- Voluntariness: Agreement to be interviewed should be voluntary and no pressure should be exerted or promises made in an effort to gain the information.

\section{Approach:}

- Explain to the interviewee the purpose of the interview and how the data will be used in the future and then obtain the interviewee's acceptance of the interview and each of the follow-up steps (verbal or written).

- Explain that the interviewee has the right to withdraw from the interview at any point and how this can be done.

- Tell the interviewee how you plan to follow-up on his/her situation.

- Follow the general considerations for interview as mentioned in the Istanbul Protocol, and explain to the interviewee how the interview will be conducted. Explain that the interviewee will be asked about the sleep pattern and eventual lack of sleep. This should be done without influencing or prompting answers by highlighting the potential consideration of sleep deprivation as ill-treatment or torture. ${ }^{6}$

- Please stress that as in any assessment, it is important to be as accurate as possible.

- The interviewer should also be aware of the risk of re-traumatisation (see the Istanbul Protocol, Chapter IV).
The potential relationship between sleep deprivation and torture can be raised at end of the interview with the purpose of providing meaning to the victim's experience and eventually alleviate guilt or trauma symptoms. 


\section{Section 2. Subjective Experience}

This section is intended to describe the sleep deprivation in the interviewee's words. Please collect the answers as verbatim as possible.

Do you think you were sleep deprived? Why?

How do you think that this affected you during detention and/or interrogation?

Does this still affect you today? If yes, can you explain how? 


\section{Section 3. Baseline: Sleep pattern before detention}

This section is intended to assess potential vulnerabilities linked to the interviewee's minimum duration of necessary sleep and circadian rhythm. It is especially relevant if the interviewee was submitted to interrogation during the night or at changing times.

Taking the months before detention as reference point, ask the following questions on normal sleep pattern and previous sleep problems before detention. ${ }^{7}$

1. How many hours on average do you sleep to feel well?

2. If you have to do a very difficult task, which hours of the day would be the best for you to get perfectly concentrated?
(a) Early morning
(b) Midday
(c) Afternoon
(d) Evening
(e) Late in the night

3. One night you remain awake to do a task between 3-5 AM. How will you feel?
(a) Perfectly fine
(b) Sleepy but fine
(c) A bit slow and confused
(d) Very slow and confused
(e) I could not do it

4. One night you are awakened by others to do a task between 3-5 AM. How will you feel?
(a) Perfectly fine
(b) Sleepy but fine
(c) A bit slow and confused
(d) Very slow and confused
(e) I could not do it

5. Previous sleep problems. Did any of the following happen to you at least 3 times a week at any time during the months before detention?
(a) Cannot get to sleep within 30 minutes [Early insomnia]
(b) Wake up in the middle of the night or too early in the morning and cannot go back to sleep [Maintenance insomnia]
(c) Have bad dreams [Nightmares and disturbing dreams]
(d) Have other sleep problems (for instance, bruxism, constant movement of the legs, snoring, snoozing...)
Explain

6. Describe contents if there were already bad dreams before detention:

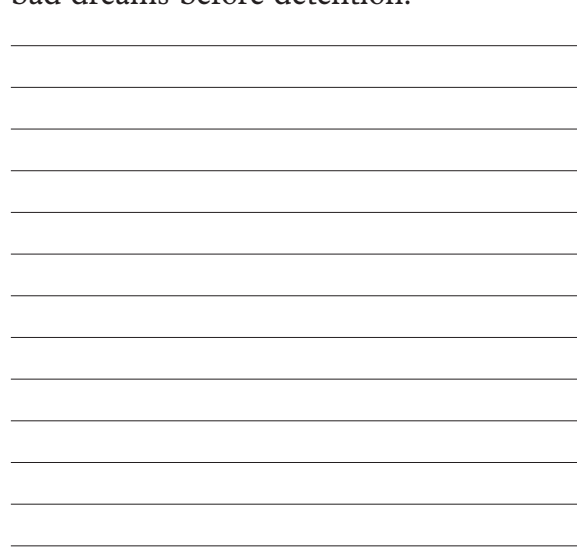

7 The questions are based on selected items adapted from the Morningness-Eveningness Questionnaire (MEQ) and Pittsburgh Sleep Quality Index (PSQI) (see Annex). 
Section 4. Diary of Sleep: What Happened?

This section is intended to provide a quantitative account of sleep deprivation as objectively as possible.

If the person, who has been subjected to the deprivation can remember each day, individualize them and give an accurate account of what happened almost day-byday then use Option 1. If the person is not able to remember each day separately, then use periods of detention as in Option 2.

If in doubt, use Option 1 whenever possible.

Note that there may be some gaps in the information but try to collect the facts in as detailed a manner as possible.

Option 1: What happened, day-by-day.

\begin{tabular}{|c|c|c|c|}
\hline & $\begin{array}{c}\text { How many } \\
\text { hours were you } \\
\text { interrogated } \\
\text { continuously? }\end{array}$ & $\begin{array}{c}\text { How many hours } \\
\text { could you sleep } \\
\text { continuously? }\end{array}$ & $\begin{array}{c}\text { Were you deliberately } \\
\text { or accidentally awoken } \\
\text { or kept awake during } \\
\text { the resting period? } \\
\text { 1. Never } \\
\text { 2. Sometimes } \\
\text { 3. Regularly } \\
4 . \text { All the time }\end{array}$ \\
\hline $1^{\text {st }}$ day & & & \\
\hline $2^{\text {nd }}$ day & & & \\
\hline $3^{\text {rd }}$ day & & & \\
\hline $4^{\text {th }}$ day & & & \\
\hline $5^{\text {th }}$ day & & & \\
\hline $6^{\text {th }}$ day & & & \\
\hline $7^{\text {th }}$ day & & & \\
\hline $8^{\text {th }}$ day & & & \\
\hline Etc. & & & \\
\hline & & & \\
\hline & & & \\
\hline & & & \\
\hline & & & \\
\hline & & & \\
\hline & & & \\
\hline & & & \\
\hline & & & \\
\hline & & & \\
\hline & & & \\
\hline & & & \\
\hline & & & \\
\hline
\end{tabular}


Option 2: Description by periods of time.

1. How did you keep track of the time?

2. Hours and distribution of sleep:

\begin{tabular}{|c|c|c|c|c|c|}
\hline Event $^{a}$ & $\begin{array}{c}\text { Estimated } \\
\text { total } \\
\text { duration } \\
\text { (hours or } \\
\text { days) }\end{array}$ & $\begin{array}{c}\text { How many } \\
\text { hours could } \\
\text { you sleep } \\
\text { continuously? } \\
\text { (estimate) }\end{array}$ & $\begin{array}{c}\text { How many } \\
\text { hours } \\
\text { were you } \\
\text { interrogated } \\
\text { continuously? } \\
\text { (estimate) }\end{array}$ & \begin{tabular}{|c}
$\begin{array}{c}\text { Were you } \\
\text { interrogated } \\
\text { during the } \\
\text { night? }\end{array}$ \\
\\
1. Never \\
2. Sometimes \\
3. Regularly \\
4. Always
\end{tabular} & $\begin{array}{c}\begin{array}{c}\text { Were you } \\
\text { awakened } \\
\text { during } \\
\text { periods of } \\
\text { sleep or rest? }\end{array} \\
\text { 1. Never } \\
\text { 2. Sometimes } \\
\text { 3. Regularly } \\
\text { 4. Always } \\
\end{array}$ \\
\hline $\begin{array}{c}\text { During } \\
\text { Transport }\end{array}$ & & $\mathrm{n} / \mathrm{a}$ & $\mathrm{n} / \mathrm{a}$ & $\mathrm{n} / \mathrm{a}$ & $\mathrm{n} / \mathrm{a}$ \\
\hline $\begin{array}{c}\text { Before } \\
\text { Interrogation }(\mathrm{s})^{\mathrm{b}}\end{array}$ & & & $\mathrm{n} / \mathrm{a}$ & $\mathrm{n} / \mathrm{a}$ & $\mathrm{n} / \mathrm{a}$ \\
\hline $\begin{array}{c}\text { During } \\
\text { Interrogation }(\mathrm{s})^{\mathrm{c}}\end{array}$ & & & & & $\mathrm{n} / \mathrm{a}$ \\
\hline After Interrogation $^{\mathrm{d}}$ & & & $\mathrm{n} / \mathrm{a}$ & $\mathrm{n} / \mathrm{a}$ & \\
\hline
\end{tabular}

a If your case does not involve an interrogation, you need to change these categories and adapt them to your needs. You may prefer to order periods according to locations (for example places of detention), authority in charge, or according to acts of mistreatment (before/after subjected to certain acts). Listen to the interviewee's account and decide which markers would be most appropriate to organize the diary of sleep.)

b From arrival until first interrogation.

From the first to the last interrogation.

d After the last interrogation.

\section{Maximum Sleep Deprivation}

During this period, please note:

- What was the longest time (number of hours) of continuous interrogation throughout the entire period of detention?

- What was the maximum number of hours that you were forced to be awaken? (you can specify more than one time, if there were different very significant situations)

\section{Chronic Sleep Deprivation 8}

- Total number of hours that the person slept during sleep deprivation (when using description day by day):

- Average number of hours in which the person is allowed to sleep by day, by the number of days that the person was detained (when using the description by stages during detention):

8 Please note that the absolute number of hours or days (see schema) may not give the full picture or even be misleading when the hours of sleep vary. By way of example, in a detention facility where regulations establish minimum sleep of 6 hours per 24 hours, the detainee may be allowed to sleep 6 hours in the beginning of day $\mathrm{X}$ and 6 hours at the end of the following day. Thus, the person will be sleep deprived for a total of 40 out of 48 hours within the two days-without contravening the regulations. This is why the distribution is as relevant as the total number of hours. 


\section{Section 5. Sleeping Conditions}

The following questions explore conditions that might affect sleeping during the time allocated to it by the authorities. If the person could not sleep during these periods, ask why. Please include all situations without taking into consideration whether this was intentionally done or not.

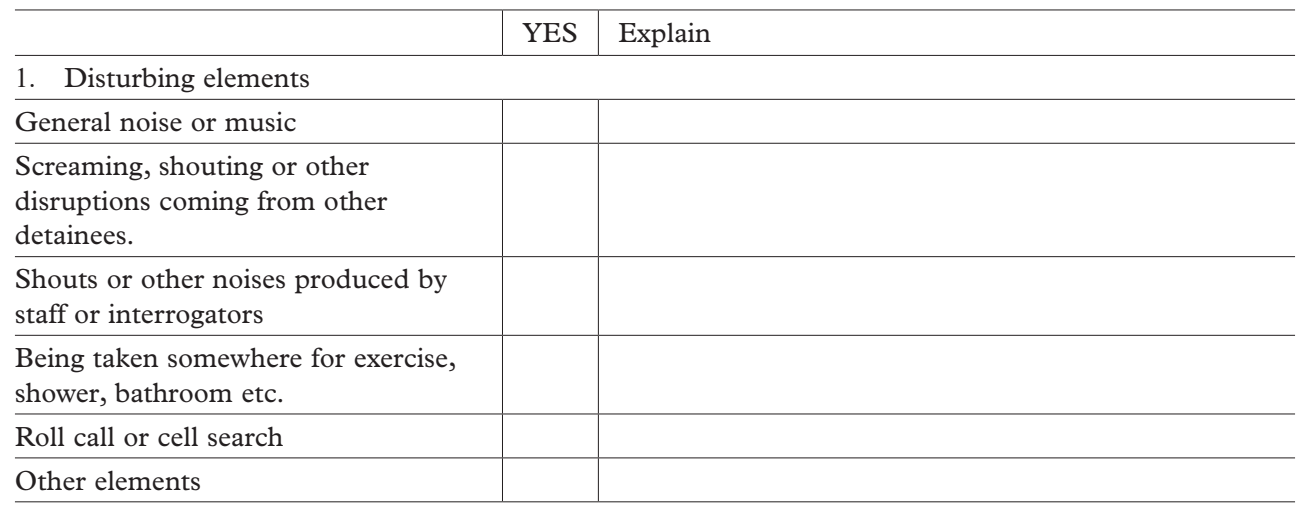

2. Acts intentionally aimed to disrupt sleep during resting periods

Water in face/body

Stress positions

Use of restraints

Forced standing or walking

Other acts causing pain that prevents you from sleeping

3. Conditions of the cell

\begin{tabular}{l|l|l}
\hline Temperature & & \\
\hline Constant light & & \\
\hline Hygiene, sanitation & & \\
\hline $\begin{array}{l}\text { Rats, mice, lice, bedbugs or other } \\
\text { insects or animals }\end{array}$ & & \\
\hline Overcrowding & & \\
\hline Lack of ventilation & & \\
\hline Size of the cell & & \\
\hline Other elements & & \\
\hline 4. Person's physical or emotional state impedes sleeping \\
\hline Pain & & \\
\hline Anxiety & & \\
\hline Fear & & \\
\hline Rumination & & \\
\hline Shame, humiliation, guilt & & \\
\hline Rage & & \\
\hline Hallucinations &
\end{tabular}




\section{Section 6. Medical and Psychological}

\section{Consequences}

This section of the Protocol should be applied by a medical or psychological expert.

- Have you ever required medical treatment for insomnia?

YES NO

If yes, describe:

- Have you suffered from previous diseases that affected sleep (especially neurological or endocrinological disorders)? YES NO

If yes, describe: 
Checklist of cognitive symptoms linked to detention ${ }^{9}$

This checklist assesses the person's cognitive symptoms during detention and interrogation and afterwards.

Column A: While you were sleep restricted, did any of these items occur to you and if yes, how often?

Column B: Did any of these symptoms improved or worsened when all situations of sleep deprivation ended, and you could sleep again (usually after your period of detention)? (only ask for items marked as "Often" or "Always" in column A)

\begin{tabular}{|c|c|c|}
\hline During your time in detention, did the following happen: & \multirow{2}{*}{$\begin{array}{l}\text { A: During sleep } \\
\text { deprivation } \\
\text { 1. Never } \\
\text { 2. Sometimes } \\
\text { 3. Often } \\
\text { 4. All the time }\end{array}$} & \multirow{2}{*}{ 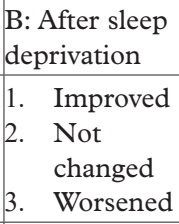 } \\
\hline Items & & \\
\hline 1. Consciousness. Did you ever lose it? & & \\
\hline $\begin{array}{l}\text { If yes: Reasons for losing consciousness: } \\
\text { (a) Beatings in head/traumatic brain injury } \\
\text { (b) Suffocation/Asphyxia } \\
\text { (c) Emotional fainting (anxiety, fear...) } \\
\text { (d) Other forms of pain } \\
\text { (e) Other }\end{array}$ & & \\
\hline $\begin{array}{l}\text { 2. Orientation. Were you able to say more or less how much } \\
\text { time you had been detained? }\end{array}$ & & \\
\hline $\begin{array}{l}\text { 3. Orientation. Did you usually know, approximately, the time } \\
\text { of the day? (morning, afternoon, evening or night) }\end{array}$ & & \\
\hline $\begin{array}{l}\text { 4. Awareness. Did you feel sleepy while not being } \\
\text { interrogated? }\end{array}$ & & \\
\hline $\begin{array}{l}\text { 5. Awareness. Did you feel sleepy most of the day while not } \\
\text { being interrogated? }\end{array}$ & & \\
\hline $\begin{array}{l}\text { 6. Concentration and Memory. Did you ever notice that you } \\
\text { could not remember basic information about yourself (e.g. the } \\
\text { name of very close family members or details of your infancy)? }\end{array}$ & & \\
\hline $\begin{array}{l}\text { 7. Concentration and Memory. Did it happen that you were } \\
\text { not able to understand even simple questions from others } \\
\text { (detainees, relatives, interrogators or prison staff)? }\end{array}$ & & \\
\hline $\begin{array}{l}\text { 8. Concentration and Memory. Were you able to recall, } \\
\text { immediately after detention, how your cell was (do not use if } \\
\text { the person was blindfolded)? }\end{array}$ & & \\
\hline
\end{tabular}

$9 \quad$ Items selected and adapted from MOCA and Brief Neuropsychological Assessment questionnaires to a context of detention and sleep deprivation (see Annex). 
During your time in detention, did the following happen:

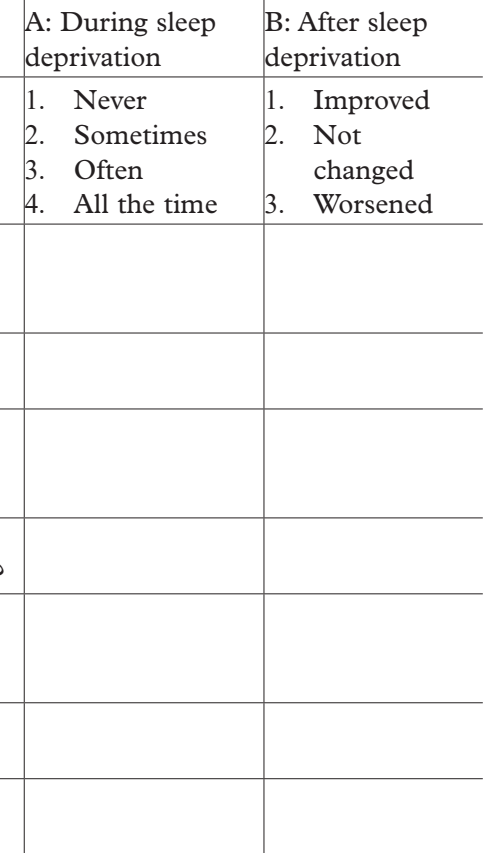

Please explain or give details of any of the above if necessary (e.g. circumstances, symptoms, subjective experience or whatever can help to understand the item). 
Checklist of emotional symptoms linked to detention ${ }^{10}$

This checklist assesses the person's emotions during interrogation and detention and interrogation and afterwards.

Column A: While you were sleep restricted, did any of these items occur to you and if yes, how often?

Column B: Did any of these symptoms improve or worsen when all sleep deprivation ended and you could sleep again? (only ask for items marked "Often" or "Always" in column A)?

\begin{tabular}{|c|c|c|}
\hline During your time in detention, did it happen to you that: & $\begin{array}{l}\text { A: During sleep } \\
\text { deprivation }\end{array}$ & $\begin{array}{l}\text { B : After sleep } \\
\text { deprivation }\end{array}$ \\
\hline Items/symptoms & $\begin{array}{ll}\text { 1. } & \text { Never } \\
\text { 2. } & \text { Sometimes } \\
\text { 3. } & \text { Often } \\
\text { 4. } & \text { All the time }\end{array}$ & $\begin{array}{l}\text { 1.Improved } \\
\text { 2. Not changed } \\
\text { 3. Worsened }\end{array}$ \\
\hline \multicolumn{3}{|l|}{ Emotions, Feelings and Somatization } \\
\hline 1. Sadness & & \\
\hline 2. Anger (at yourself or others) & & \\
\hline 3. Terror, Fear. & & \\
\hline 4. Anxiety including problems breathing, or panic attacks & & \\
\hline $\begin{array}{l}\text { 5. Pain without apparent reason (i.e. stomachache, } \\
\text { headaches or others) }\end{array}$ & & \\
\hline \multicolumn{3}{|l|}{ Acting emotions } \\
\hline $\begin{array}{l}\text { 6. Self-Harm. Urge to act against himself/herself (e.g., } \\
\text { cutting or hitting) }\end{array}$ & & \\
\hline 7. Suicide ideas. Thoughts about taking your own life & & \\
\hline $\begin{array}{l}\text { 8. Suicide plans or actions. You had a defined plan or even } \\
\text { tried to kill yourself }\end{array}$ & & \\
\hline 9. Apathy. Abandonment due to complete hopelessness & & \\
\hline \multicolumn{3}{|l|}{ Secondary Emotions - Emotions related to others } \\
\hline \multicolumn{3}{|l|}{ 10. Shame. Intense humiliation or debasement } \\
\hline \multicolumn{3}{|l|}{ 11. Guilt. Self-accusation. Intense remorse } \\
\hline \multicolumn{3}{|l|}{ Detaching emotions } \\
\hline \multicolumn{3}{|l|}{$\begin{array}{l}\text { 12. Dissociation. Feeling everything unreal or dazed, like if } \\
\text { everything did not really happen to you. }\end{array}$} \\
\hline \multicolumn{3}{|l|}{ Positive Emotions } \\
\hline \multicolumn{3}{|l|}{ 13. Control. Calm, feeling in charge. } \\
\hline 14. Happiness. Moments of joy despite everything & & \\
\hline
\end{tabular}

10 Items selected and adapted from the Positive and Negative Affect Schedule (PANAS) and Profile of Mood States (POMS) to a context of detention and sleep deprivation. 
Severity of pain and suffering. ${ }^{11}$

A person under sleep deprivation may feel pain and suffering due to it. The level of pain and suffering is relevant in the legal world and needs to be assessed. Pain is the unpleasant sensory experience associated with sleep deprivation. Your body is in pain.
It relates to how you feel it. Suffering is the unpleasant subjective experience associated with sleep deprivation. You suffer because of your pain. It relates to how you life it.

Please, according to what happened during your worst moment of sleep deprivation mark a cross in each line as appropriate

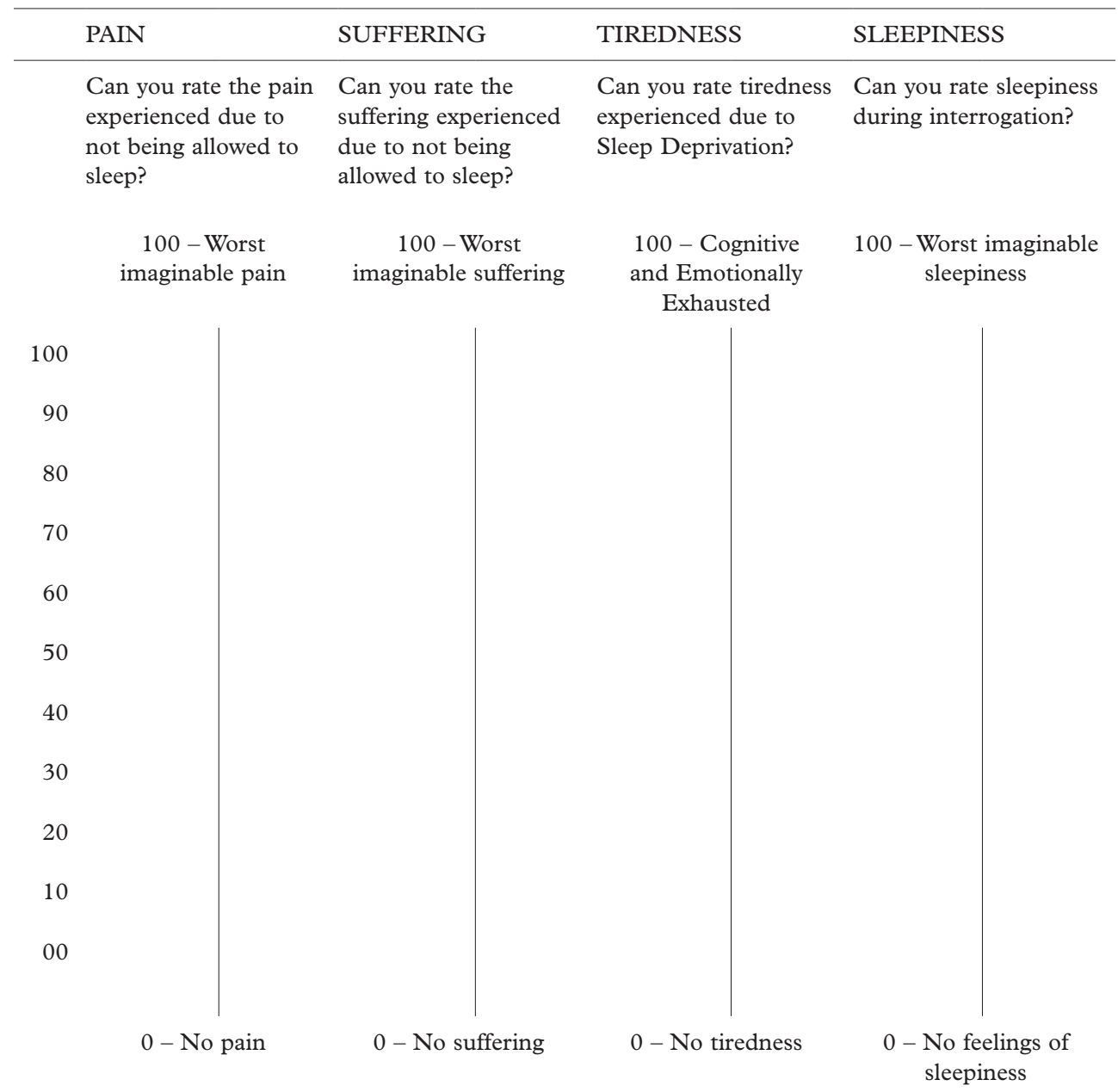

11 Measures based on the Visual Analog Scale for Pain (See for a review Hawker, Mian, Kendzerska, \& French, 2011). 


\section{Long term symptoms}

This section reflects general and specific symptoms.

General symptoms. The Protocol is part of an overall assessment that will normally include an Istanbul Protocol, where there is a comprehensive assessment of medical and psychological consequences of torture.

As far as sleep deprivation is part of an overall system of torture, where cumulative and combined effects are seen, it is difficult to attribute specific long term problems to sleep deprivation.

If possible:

(a) Tailor the clinical interview to symptoms that the person attributes to long term medical and psychological consequences of sleep deprivation.

(b) Use clinical scales detailed in Annex including in the instructions that the person considers the answers in relation to sleep deprivation. For instance, if the PCLC-V is used to assess symptoms of post-traumatic stress disorder, explain the person that each item (flashbacks, avoidance behaviours, intruding thoughts...) should be in relation to sleep deprivation (i.e., flashbacks on how was sleep deprivation, avoidance of sleeping time, recurrent thoughts regarding nightmares or not being able to sleep etc.). Update questionnaires to the most recent and reliable version available at the moment of doing the assessment.

ICD Diagnosis:

Additional Diagnosis: 
Specific Symptoms. Use the World Health Organization's criteria (ICD) for sleep related disorders in force at the time of assessment. Consider here only those sleep disorders in which emotional or physical causes during detention are considered to be a primary factor, and which are not due to other identifiable physical or psychological disorders that appeared after detention. Consider, at least:
1 Insomnia. A condition of unsatisfactory quantity and/or quality of sleep, which persists for a considerable period of time, including difficulty falling asleep, difficulty staying asleep, or early final awakening.

2 Hypersomnia. Hypersomnia is defined as a condition of either excessive daytime sleepiness or sleep attacks not secondary to insomnia.

3 Inversion of circadian/sleep rhythm. The person sleeps during day and is awoken during nights.

4 Sleepwalking [somnambulism]. The individual gets out of bed, usually during the first third of nocturnal sleep, and walks about, exhibiting low levels of awareness, reactivity, and motor skill. Upon awakening, there is usually no recollection of the event.

5 Sleep terrors [night terrors]. Nocturnal episodes of extreme terror and panic associated with intense vocalization, motility, and high levels of autonomic discharge. The individual sits up or gets up, usually during the first third of nocturnal sleep, with a panicky scream. Quite often he or she rushes to the door as if trying to escape, although very seldom leaves the room. Recall of the event, if any, is very limited.

6 Nightmares. Dream experiences loaded with anxiety or fear. There is very detailed recall of the dream content. The dream experience is very vivid and usually includes themes involving threats to survival, security, or self-esteem. Quite often there is a recurrence of the same or similar frightening nightmare themes. During a typical episode there is a degree of autonomic discharge but no appreciable vocalization or body motility. Upon awakening the individual rapidly becomes alert.

7 REM Sleep Behavior Disorder . The person physically acts out vivid, often unpleasant dreams with vocal sounds and sudden, often violent arm and leg movements during REM sleep. It is sometimes called dream-enacting behavior. Differential diagnosis with Sleep Terrors requiere Actigraphy or Polysomnographic Tests.
[0] No insomnia

[1] More than 1 hour for falling asleep

[2] Difficulty staying asleep

[3] More than two hours early wakening

[4] Difficulties in all areas

[0] No

[1] Sometimes

[2] Always

[0] No

[1] Sometimes

[2] Always

[0] No

[1] Sometimes

[2] Always

[0] No

[1] Sometimes

[2] Always
[0] No

[1] Sometimes

[2] Always
[0] No

[1] Sometimes

[2] Always 


\section{Section 7. Legal Assessment of Sleep Deprivation}

The legal qualification of sleep deprivation (torture per Article 1 of the CAT, or CIDT per Article 16 of the UNCAT or below the threshold of Article 16 of the UNCAT) would depend upon the specific circumstances of the case, including whether other forms of ill-treatment occurred or not. Try to seek information that may be useful for the legal assessment of the case. The below questions relate to two key elements to be analyzed to distinguish torture and CIDT in the legal domain: (1) Purpose and Outcome and (2) Intentionality

\section{Purpose and outcome}

These questions are essential if you are going to do research. In case that sleep deprivation was linked to interrogation, these are the main variables that you will use to compare and relate to all the other measures. They are less useful if you are collecting information for medical documentation of cases.

Purpose of Sleep Deprivation ${ }^{1}$

1. Was sleep deprivation related to obtaining information?

2. Was sleep deprivation related to obtaining a confession?

3. Did you sign a confession (whether true or not)?

4. Did you have fabricated memories?

"Fabricated memories" are statements that the person recognized as true while they were not, and the person honestly thought at that moment that they were true. It is an induced answer prompted under disorientation/confusion by suggestions made by the interrogator. The person rejects them when recovers control.

5. Did you have false memories? "False memories" are elements that the person believes as true while they are not, produced by the pressure of the situation. The person doubts if they are real memories or not even after recovering control.

6. Did you have false memory after interrogation? Some persons can have false memories months or even years after the events. The person cannot distinguish new and false memories.

7. Do you think that sleep deprivation was related to any other purpose? Can you explain or provide examples: (punishment, humiliation, submission etc.)

$\begin{array}{cc}\text { Yes } & \text { No } \\ \text { Yes } & \text { No } \\ \text { Yes } & \text { No } \\ \text { Yes } & \text { No }\end{array}$

Yes $\quad$ No

Yes $\quad$ No

Yes $\quad$ No
1 Questions that may help to answer the scale: Can I ask you whether there was confession? We do not need to enter details, unless you specifically wish to do so; Did you provide any information against your will? Did you sign a statement or confession? - We do not need to know if the contents were true, partially true or untrue; Did you ever during the interrogation recover in memory anything that were not able to remember before interrogation? Were these memories kept in time or new memories appeared that did not exist before the interrogation? 
Assessment of the intention behind the use of sleep deprivation ${ }^{12}$

These questions aim to document the intention of using sleep deprivation and as such, the use of sleep deprivation was not incidental or simply a regular aspect of the normal interrogation or detention conditions.

1. Purpose made explicit. During the interrogation, the interrogator mentioned sleep manipulation/deprivation (either positive ("let him sleep"), or negative ("you will continue until...")).
a. No
b. Yes.
Explain:

2. Purpose made explicit. You heard that someone gave orders related to your sleep.
a. No
b. Yes.
Explain

3. Pattern. Night interrogations.
a. No
b. Yes.
Explain

4. Context criterion. Physical environment impeded sleeping. ${ }^{13}$
a. No
b. Yes.
Explain:

5. Context criterion. Actions that impeded sleeping (e.g., shouting/opening the door. without any other reason).
a. No
b. Yes.
Explain:

6. Aim/Objective. Any change occurred after signing a confession or statement.
a. No
b. Yes.
Explain:

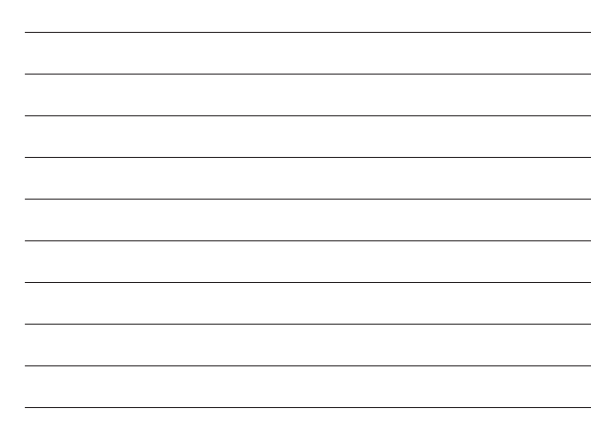

12 Items selected and adapted from the Intentionality Assessment Checklist (IAC).

(Pérez-Sales, 2017)

13 If you know the answer from previous questions, no need to repeat the question. 
7. Fragmentation. Person is allowed rest time in cell in a fragmented and insufficient manner (in various times of day and for short and variable periods of time)
a. No
b. Yes.
Explain:

8. Prolongation. Sleep deprivation is maintained after the person's explicit complaint of need to sleep.
a. No
b. Yes.
Explain:

10. Systematicity - Planification. Other persons explained a similar pattern (Do you know of other persons who experienced similar problems with sleep?).
a. No
b. Yes.
Explain:

9. Viciousness criteria. Reiteration in spite that the person falls asleep during interrogation (awakening manoeuvres).
a. No
b. Yes.
Explain:

11. Prolongation: More than 24 hours without being allowed to sleep.
a. No
b. Yes.
Explain:

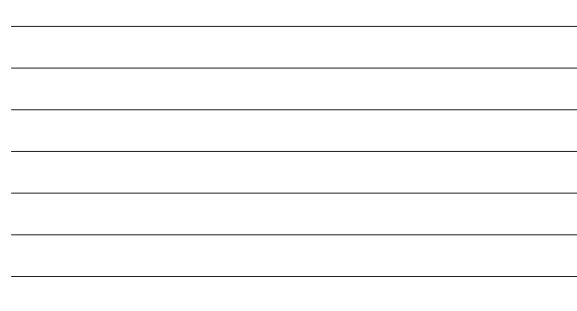




\section{Annex-Additional Questionnaires}

The Protocol can be complemented with the following assessment tools.

\section{Torturing Environment}

Torturing Measures profiles of torturing environments in 8 dimensions: Manipulation

Environment Scale of environment, fear/threats, moderate pain, critical pain-amputation-death, sexual identity, need to belong- collective self, identity, meaning, purpose and coercive interrogation. References: Pérez-Sales P (2017). Psychological torture. Definition, Evaluation and Measurement. Routledge. Chapter 18 and Annex 5.

\section{Interrogation Practices}

The Scale for Coercive The scale for coercive interrogation has 36 items and includes 9 dimensions: Interrogation rapport-building, cognitive interviewing, threats, confrontation-imposition, deception, emotional manipulation, cognitive manipulation, moral manipulation and physical coercion.

\section{Clinical measures}

Posttraumatic Stress Disorder

The Posttraumatic Checklist Civilian Version - 5 (PCL-C-5), a 20-item questionnaire that provides a diagnosis of PTSD according to DSM-V Criteria. ${ }^{1}$ There are also short screening versions available, like the BSS for PTSD. ${ }^{2}$ The International Trauma Questionnaire is a 12 -item measure that provides diagnoses of PTSD and Complex PTSD according to ICD-1.

The Dissociative Experiences Scale (DES-II) provides a measure of states of dissociation. Can be tailored to reaction within detention periods.

Daily Functioning Consider measures that assess the autonomy of the person after release from detention (e.g., work, study, community and family life). 


\section{The following tools are referenced in the Sleep Deprivation Protocol}

\section{Morningness-Eveningness Questionnaire} (MEQ). Horne JA and Östberg O. (1976) A self-assessment questionnaire to determine morningness-eveningness in human circadian rhythms. International Journal of Chronobiology. 4:97-100.

Pittsburgh Sleep Quality Index (PSQI). The measure consists of 19 individual items, creating 7 components that produce one global score, and takes 5-10 minutes to complete. Buysse, Daniel J.; Reynolds, Charles F.; Monk, Timothy H.; Berman, Susan R.; Kupfer, David J. (May 1989). "The Pittsburgh sleep quality index: A new instrument for psychiatric practice and research". Psychiatry Research. 28 (2): 193213. doi:10.1016/0165-1781(89)90047-4.

\section{Montreal Cognitive Assessment}

(MOCA). 30 items assessing neurocognitive functioning. Administration takes around 15'. Ziad S. Nasreddine MD, et al, The Montreal Cognitive Assessment, MoCA: A Brief Screening Tool For Mild Cognitive Impairment, Journal of the American Geriatric Society, 30 March 2005.

\section{Brief Neuropsychological Assessment}

- Mini Mental State Examination. 30 items measure that screens for cognitive impairment linked to medical conditions. Folstein MF, Folstein SE, McHugh PR. "Mini-mental state": a practical method for grading the cognitive state of patients for the clinician.

J Psychiatr Res . 1975;12:189-19.

\section{Positive and Negative Affect Schedule}

(PANAS). Short scale that consists of two 10 -item mood scales to measure emotional reactions to a given situation. D. Watson, L.A. Clark, and A. Tellegen (1988). Development and Validation of Brief Measures of Positive and Negative Affect: The PANAS Scales. Journal of Personality and Social Psychology, 54, 1063-1070.

Profile of Mood States (POMS). 65 items assessing 7 different mood domains. McNair, D., Lorr, M., \& Droppleman, L. (1971). Manual for the Profile of Mood States. San Diego: Educational and Industrial Testing Service.

\section{Intentionality Assessment Checklist} (IAC). It is an aid to assess the alleged torture perpetrator's intent. It helps to systematically assess all potentially pertinent elements, without aiming to provide a score but an overall perspective of elements relevant to intentionality. Pau Pérez-Sales, Psychological Torture, Routledge. p. 375

\section{MQPL+: Measuring the Quality of Prison Life (MQPL) and Staff Quality of Life (SQL). Liebling, A., Hulley, S. and Crewe, B. (2011), 'Conceptualising and Measuring the Quality of Prison Life', in Gadd, D., Karstedt, S. and Messner, S. (eds.) The Sage Handbook of Criminological Research Methods. London: Sage}




\section{References:}

Beattie, L., Kyle, S. D., Espie, C. A., \& Biello, S. M. (2015). Social interactions, emotion and sleep: A systematic review and research agenda. Sleep Medicine Reviews, 24, 83-100. https://doi. org/10.1016/j.smrv.2014.12.005

Cakal. E. (2019). Befogging reason, undermining will: Understanding sleep deprivation as torture and other Ill-treatment in international law. Torture Fournal 29(2), 11-22. https://doi. org/10.7146/torture.v29i2.109620

Hirshkowitz, M., Whiton, K., Albert, S. M., Alessi, C., Bruni, O., Don Carlos, L., ... Adams Hillard, P. J. (2015). National Sleep Foundation's sleep time duration recommendations: methodology and results summary. Sleep Health, 1(1), 40-43. https:// doi.org/10.1016/j.sleh.2014.12.010

Gudjonsson, G. H. (2003). The psychology of interrogations and confessions. A handbook. London: Wiley.

Hawker, G. A., Mian, S., Kendzerska, T., \& French, M. (2011). Measures of adult pain: Visual Analog Scale for Pain (VAS Pain), Numeric Rating Scale for Pain (NRS Pain), McGill Pain Questionnaire (MPQ), Short-Form McGill Pain Questionnaire (SF-MPQ), Chronic Pain Grade Scale (CPGS), Short Form-36 Bodily Pain Scale (SF. Arthritis Care and Research, 63(SUPPL. 11), 240-252. https://doi. org/10.1002/acr.20543

Jackson, S. A., Martin, G. D., Aidman, E., \& Kleitman, S. (2017). Acute short-term sleep deprivation does not affect metacognitive monitoring captured by confidence ratings: a systematic literature review. Metacognition and Learning. https://doi.org/10.1007/s11409-0179177-y

Leo, R. A. (1996). Inside the interrogation room. The fournal of Criminal Law \& Criminology, 86(2), 266-303.

Lim, J., \& Dinges, D. F. (2010). A meta-analysis of the impact of short-term sleep deprivation on cognitive variables. Psychological Bulletin, 136(3), 375-389. https://doi.org/10.1037/ a0018883

Lowe, C. J., Safati, A., \& Hall, P. A. (2017). The neurocognitive consequences of sleep restriction: A meta-analytic review. Neuroscience and Biobehavioral Reviews, 80, 586-604. https://doi.org/10.1016/j. neubiorev.2017.07.010

Perez-Sales, P. (2017). Psychological Torture: Definition, Evaluation and Measurement. Routledge Books. London.

Philibert, I. (2005). Sleep loss and performance in residents and nonphysicians: a meta-analytic examination. Sleep, 28(11), 1392-1402.

Pires, G. N., Bezerra, A. G., Tufik, S., \& Andersen, M. L. (2016). Effects of acute sleep deprivation on state anxiety levels: a systematic review and meta-analysis. Sleep Medicine, 24, 109-118. https://doi.org/10.1016/j.sleep.2016.07.019

Reynolds, A. C., \& Banks, S. (2010). Total sleep deprivation, chronic sleep restriction and sleep disruption. Progress in Brain Research (Vol. 185). Elsevier B.V. https://doi.org/10.1016/ B978-0-444-53702-7.00006-3

Schrimpf, M., Liegl, G., Boeckle, M., Leitner, A., Geisler, P., \& Pieh, C. (2015). The effect of sleep deprivation on pain perception in healthy subjects: a meta-analysis. Sleep Medicine, 16(11), 1313-1320. https://doi.org/10.1016/j. sleep.2015.07.022

Watson, N. F., Badr, M. S., Belenk, G., \& Bliwise, D. L. (2015). Recommended amount of sleep for a healthy adult. American Academy of Sleep Medicine and Sleep Research Society, 38(6), 843844. https://doi.org/10.5665/sleep.4716

Waters, F., Chiu, V., Atkinson, A., \& Blom, J. D. (2018). Severe Sleep Deprivation Causes Hallucinations and a Gradual Progression Toward Psychosis With Increasing Time Awake. Frontiers in Psychiatry, 9, 303. https://doi. org/10.3389/fpsyt.2018.00303

United States Army. (2006). Appendix M of the Army Field Manual Human Intelligence Collector Operations, FM 2-22.3 of September 2006.

\section{Court judgments:}

ECHR. (2004). Bati v. Turkey, 33097/96 and $57834 / 00$.

ECHR. (2007). Bagel v. Russia, 37810/03.

ECHR. (2011). Mader v. Croatia, 56185/07. 
ECHR. (2012). Strelets v. Russia, 28018/05.

ECHR. (2016). Sadretdinov v. Russia, 17564/06.

ICTY. (2002). Prosecutor v. Krnojelac. Case No. IT-97-25 (Trial Chamber) 15 March 2002.

ICTY. (2006). Naletilic and Matinovic. Appeal Judgement, 3 May 2006.

Inter-American Commission on Human Rights.

(2003). Maritza Urrutia v. Guatemala. 27

November 2003. Series C No. 103.

Concluding Observations by the UN Committee Against

Torture

UN Committee Against Torture (2006).

Conclusions on USA. CAT/C/USA/CO/2.

UN Committee Against Torture (2014).

Conclusions on USA. CAT/C/USA/CO/3-5.

UN Committee Against Torture (1998).

Conclusion on Israel. CAT/C/ISR/CO/5. 